\title{
Gubareva T.A. \\ The process of implementing the model of education of a culture of tolerant communication among university students
}

FSBEI HE Orenburg State Agrarian University

(Russia, Orenburg)

doi: $10.18411 /$ sr-10-02-2020-37

idsp: sciencerussia-10-02-2020-37

\section{Abstract}

The article says about practical realization of education's model of tolerant communication's culture of the students. The tasks, principles and organizational - methodic aspects of the pedagogical experiment are analyzed and criteria and indicators that allow getting the objective information about the effectiveness of our work are presented. The article is for teachers of universities, post - graduate students, students.

Key words: structural-functional model of education, culture of tolerant communication.

The purpose of the experimental work was: to test the structural-functional model of educating the culture of tolerant communication among students in the educational process of the university and the pedagogical conditions for its implementation. identified:

In accordance with the goal, the following tasks of the experimental work were

1. To study the state and level of development of the culture of tolerant communication among university students in experimental groups;

2. Experimentally check the influence of pedagogical conditions on the education of a culture of tolerant communication among students;

3. Based on the results of the experimental work, to develop methodological recommendations to help pedagogical groups on the development of a culture of tolerant communication among university students.

When organizing the experimental work on the education of a culture of tolerant communication among university students, we determined the dominant principles:

- dialogue of cultures (dialogue interaction that ensures adequate mutual understanding and spiritual mutual enrichment of representatives of different cultural communities);

- humanism (recognition of the value of a person as a person, his right to freedom, development and manifestation of his abilities);

- co-creation of the subjects of interaction (development of the initiative and independence of students, joint creative solution by the teacher and student of emerging problems);

The following materials were prepared for the experiment:

1. Practical course "Education of a culture of tolerant communication among university students" (guidelines).

2. Training program for tolerant communication for students of higher educational institutions.

3. The system of exercises aimed at the development of the three sides of communication, manifested simultaneously (communication, interaction, perception).

4. Methodological recommendations for teachers of English at the university (Department of Economics, OSAU). 
Before considering the organizational and methodological aspects of the pedagogical experiment, it was necessary to solve the problem of choosing criteria and indicators that would allow obtaining objective information about the effectiveness of the work being done.

The main indicator of the effectiveness of pedagogical activity is the degree of development of the culture of tolerant communication among university students.

As initial, we determined the levels of upbringing of the culture of tolerant communication among university students.

Based on the previously developed criteria for a culture of tolerant communication about the level of this integrative quality, we judged by the characteristics of its components: cognitive, emotional, evaluative and behavioral.

The main goal of the ascertaining stage of the experimental work is to identify the level of culture of tolerant communication among university students.

A high level was characterized by the presence of complete, correct knowledge about the phenomenon of the culture of tolerant communication.

The average level was characterized by the presence of sufficient knowledge about the culture of tolerant communication.

The low level was characterized by a general idea of a culture of tolerant communication.

All three levels are interconnected, and each previous determined the next, including in its structure.

In order to determine the levels of development of the components (cognitive, emotional-evaluative, behavioral) of the culture of communication, we used specific methods.

So, to determine the cognitive component, students were presented with a questionnaire and a questionnaire "Personality traits with a culture of tolerant communication" with 16 characteristics. These characteristics were highlighted based on the analysis of the well-known test by R. Cattell.

Those three qualities that scored the most points were the core of a person who owns a culture of tolerant communication (from the point of view of this group).

To conduct a study of tolerant communication culture, we offered tests of empathic abilities (empathy - empathy). The author of the first test I.M. Yusupov identified five levels.

To assess interpersonal relationships, students were offered a test questionnaire "Qsorting", developed by V. Stefanson.

In total, six styles stood out: dependence - independence; sociability - non-sociability; acceptance of the struggle; avoidance of struggle.

As a means of increasing the level of culture of tolerant communication among students, the practical course "Education of tolerance" was used. This allowed the term "tolerance" to be put into circulation, to instill the skills and abilities of positive interaction with representatives of various cultures, nationalities, faiths, social groups, views, and beliefs.

The positive interaction of students - representatives of different cultures was achieved through the forms and methods of the problem-search, imitation-role nature in the formation of structural components: cognitive, emotional-evaluative and behavioral.

In the formation of the cognitive component of the culture of communication, our main task was to transfer to students as much knowledge as possible.

At the same time, a lecture was used - a press conference, which is a form of training that allows you to introduce students to basic concepts.

After this lecture, we conducted a staging game on the topic: "Me and the people around me."

In order to systematize previously acquired knowledge on the culture of tolerant communication, we used various cognitive games.

In particular, we carried out:

- cognitive game "One among strangers, a stranger among his own." 
- cognitive game, "Dialogue of cultures", "Agent".

In the formation of the emotional-evaluative component, pedagogical efforts were aimed at developing students' value attitude to the culture of tolerant communication, as a universal value and a means of ensuring mutual understanding and cooperation, the development of qualities such as tolerance, mutual understanding, respectful attitude to people, tolerance, sociability and communicativeness, friendliness, sensitivity, politeness, sympathy, etc.

In our study, we used such a form of the educational process as a lecture together, which is carried out in the form of a dialogue between two lecturers.

Among the ongoing activities, it should be noted such a form of training as a discussion seminar that forms the students' beliefs based on the information they received at a lecture or in the course of independent work.

To consolidate the emotional and evaluative skills of the culture of tolerant communication, business and role-playing games were conducted in which the culture of tolerant communication was imitated.

It should be noted that the main emphasis was placed on the development of the behavioral component. Skills were instilled in students on the basis of an active moral position, characterized, as a rule, by goodwill, tact, restraint. In this case, it was important to achieve coordination of the levels of formation of ideas and judgments about the substantive side of the culture of communication, its manifestation in the students' practice and their emotional reactions.

This is achieved through the application of the method of problem situations, which involves the consideration of problem situations that may arise when communicating with representatives of different cultures, nationalities, faiths, social groups, and views. The student's task is to build a model of his behavior, find the most optimal and correct solution, all possible solutions to this situation.

1. The task is an illustration. A concrete example from practice or from fiction illustrates situations of interaction between pupils, negative and positive consequences of actions, and the effectiveness of using certain examples.

2. The assessment task. Students are invited to describe the specific event and the measures taken. Their task: to assess the correctness of behavior in a particular situation with other people, the significance and consequence of the situation and the measures taken.

3. The task is exercise. Students work individually or collectively (microgroups of 3-5 people). They study the proposed situation, after which they develop an action plan and make informed decisions in accordance with promising and relevant tasks of the activity.

At all stages of the work, various pedagogical technologies were used.

So, gaming technology, problem technology can permeate all the steps of forming the integrative quality of a "culture of tolerant communication" of an individual.

The technology of problem education was used mainly in the formation of positive interaction. The practical significance of problem-based learning is that it is successfully implemented with students of different age groups, with different cognitive abilities at all stages of training.

To develop students' skills and positive interpersonal communication skills, we have developed a system of exercises that take into account the three sides of communication, manifested simultaneously (communication, interaction, perception). Based on this, this system of exercises was presented in three directions, depending on the development of which particular skills and pedagogical efforts were directed.

Communication as an exchange of information was organized using the following exercises: communication ball bearing, a chain of how to be tolerant in communication, I am a statement / You are a statement. 
In order to ensure communication as interaction, the following exercises were used: actions with objects, a web of prejudice, reincarnation, at a photo exhibition.

Communication as a process of perception and understanding of another person was realized using the following exercises: what are we like, science fiction writers, communication space ..

As a result of using these forms and methods, the positive interaction of the participants in the educational process manifests itself in sociability (characterized by contact, the desire for emotional manifestations in communication both in the group and beyond), in the tendency to "struggle" (the person's active desire to participate in group life to seek a deeper status in the system of interpersonal relationships), in the ability to avoid "struggle" (the desire to get away from group disputes and conflicts, the tendency to compromise $\mathrm{m}$, joint definition of activity goals, sharing its planning, distribution of forces and means on the basis of every opportunity).

Thus, the assumption that the development of a culture of tolerant communication among students is possible if the development of knowledge about this area of social reality becomes the basis for conscious entry into it and the establishment of a tolerant attitude towards its subjects, is mainly confirmed in the course of the study.

Tolerance in fostering a culture of communication among students has revealed the inner side of the relationship of subjects of interpersonal interaction.

An indicator of the importance of the process of developing a culture of tolerant communication among students was made by the participants, for example, "they felt the value of the acquired abilities that help to fully interact with other people." 